\title{
Prevalence of Vibrio cholerae in human-, poultry-, animal excreta and compost samples
}

\author{
Md. Aftab Uddin, ${ }^{1}$ Md. Wali Ullah ${ }^{1}$ and Rashed Noor ${ }^{1 *}$ \\ ${ }^{I}$ Department of Microbiology, Stamford University Bangladesh, 51 Siddeswari Road, Dhaka 1217, Bangladesh
}

Received 18 September 2012/Accepted 16 November 2012

\begin{abstract}
Transmission of Vibrio cholerae might take place in water bodies that often undergo contamination with human-, poultry- and animal excreta. In the present study, wastes from all three categories were analyzed microbiologically. Twelve poultry excreta samples, 12 human excreta samples and 12 cowdung samples were examined for the presence of $V$. cholerae. High prevalence of $V$. cholerae was found in each of the samples and the highest prevalence was observed for human excreta samples $\left(2.2 \times 10^{8}\right.$ cfu/g). Besides, 24 compost samples, which were prepared using human feces, were tested. The load of $V$. cholerae was found lower in the compost samples (from 0 to $2.2 \times 10^{3} \mathrm{cfu} / \mathrm{g}$ ) than that of the excreta samples. The study of antibiogram showed that all the isolates were resistant against ampicillin, erythromycin, tetracycline, chloramphenicol, nalidixic acid, meropenem and cefotaxime.
\end{abstract}

Key words: Vibrio cholerae; human excreta; personal hygiene; domestic animal; compost

Cholera in human result in profuse, watery diarrhea that can lead to severe dehydration and death. The infection begins with ingestion of Vibrio cholerae from contaminated water, food and disperse of biological wastes into nearby surrounding sources. In Bangladesh, diarrheal disease is estimated to be the fourth biggest killer of children and $V$. cholerae is considered as the only causative agent responsible for cholera endemics in Bangladesh and neighbouring countries (1-6). During late 1995 and 1991, cases of cholera attributable to $V$. cholerae $\mathrm{O} 1$ in various regions of Bangladesh, but during 1992 and 1993, the new strain, V. cholera 0139 Bengal was first emerged and caused large epidemics of cholera $(4,7)$.

The practice of open defecation in the rural areas of Bangladesh as well as the lack of adequate practice of personal and domestic hygiene have been implicated in the transmission of many infectious diseases including the enteric ones, such as cholera, typhoid, hepatitis, polio, cryptosporidiosis, ascariasis, and schistosomiasis (8). The World Health Organization (WHO) estimates that 2.2 million people die annually from diarrheal diseases and that $10 \%$ of the population of the developing world are severely infected with intestinal worms related to improper waste and excreta management (8). Human- and animal excretatransmitted diseases predominantly affect children and most of the deaths occur due to diarrhea in the developing countries including Bangladesh (9).

Manure, in the wider sense refers to all substances added to the soil in order to increase the supply of plant

${ }^{\ddagger}$ Corresponding Author. Mailing address: Dr. Rashed Noor, Department of Microbiology, Stamford University Bangladesh, 51, Siddeswari Road, Dhaka, Bangladesh; Email: noor.rashed@yahoo.com. nutrients (10). The application of organic manures has the aim of increasing soil fertility, thus productivity. Cow dung is often used as organic manure in many parts of the developing world to reduce the dependency on chemical fertilizers. Cow dung provides food for a wide range of animal and fungal species, which break it down and recycle it into the food chain and into soil, thus, cow dung increases the efficiency of mineral fertilizers by improving properties of the soil (11), but it may possess potential health risks if the pathogens are not eliminated. Parallel to cow dung, many countries (Finland, China, Norway) use human feces as manure after composting, which is a method that can be used to effectively treat human excreta for safe recycling of the plant nutrients present as fertilizers (12). Composting transforms organic matter into a stable product consisting of a humus-like substance (13). Moreover, compost can be directly used in the agricultural fields as fertilizer in addition to cow dung. Therefore, safe application of such manures in agricultural field is essential to minimize public health hazards.

Poultry and poultry products are widely used as one of the main protein source in Bangladesh. Proper management of poultry and poultry products are necessary because different species of pathogenic microorganisms mainly Salmonella, Campylobacter, Vibrio have been reported in poultry products (14-17). Therefore, improper management and disposal of poultry excreta may be related to endemic outbreaks of cholera in Bangladesh.

Along these lines, the present study was designed to isolate, identify and quantify $V$. cholerae from human excreta, poultry excreta and cow dung. The results were compared with that of compost samples. The antibiotic susceptibility patterns of the isolates were also investigated. 


\section{MATERIALS AND METHODS}

Excreta sample collection. Twelve human excreta and 12 poultry excreta samples were collected using sterile cotton swab. Cow dung samples were collected with the help of sterile spatula.

Preparation and collection of Compost Samples. Pits having size of 3 ' in diameter and 4' in length were constructed for composting. Human excreta were dumped inside the pits. Trace amount of ash or lime was mixed with the excreta. The pits were covered with leaf and grass which were then allowed to stay for at least 6 months for composting. A total of 24 compost samples were then collected in sterile plastic container and transported immediately to the laboratory.

Enrichment and Isolation of $\boldsymbol{V}$. cholerae. Samples were enriched in alkaline peptone water (APW) (Difco Laboratories, Detroit, Mich.) at $37{ }^{\circ} \mathrm{C}$ for 6 to $8 \mathrm{~h}$ before isolation (18). Enriched samples were then subjected to 10 fold serial dilution up to $10^{-5}$. From $10^{-2}$ and $10^{-4}$ dilutions, $0.1 \mathrm{ml}$ samples were inoculated onto thiosulfate citrate bile salt sucrose (TCBS) agar (Difco Laboratories, Detroit, Mich) and incubated at $37^{\circ} \mathrm{C}$ for 18 to $24 \mathrm{~h}$. Moreover, nutrient agar was also used for the determination of total viable bacteria.

Confirmation of $\boldsymbol{V}$. cholerae. After incubation, sucrose fermenting yellow colored colonies on TCBS agar were further streaked on to taurocholate tellurite gelatin agar (TTGA) for confirmation of $V$. cholerae and incubated at $37{ }^{\circ} \mathrm{C}$ for 48 hours. Characteristic black centered colonies were selected and screened for the presence of cytochrome oxidase and gelatinase activity by subculturing onto gelatin agar media. All the colonies, which were found to harbor cytochrome oxidase and showed gelatinase activity, were then taken for further confirmation by biochemical tests (triple sugar iron (TSI) agar test, motility test, Voges-Proskauer (VP) test and salt tolerance test) according to 'Microbiological Laboratory Manual' (18).

Determination of antimicrobial susceptibility by modified Kirby-Bauer method. All the isolates of $V$. cholerae were tested for antibiotic susceptibility against 10 antibacterial drugs by modified Kirby-Bauer method (19) on Mueller-Hinton Agar (Difco, Detroit, MI) media using antibiotic discs (NeoSensitabs, Rosco, Denmark) including chloramphenicol $(30 \mu \mathrm{g})$, nalidixic acid (30 $\mu \mathrm{g})$, meropenem $(30 \mu \mathrm{g})$, cefotaxime $(30 \mu \mathrm{g})$, ampicillin $(10 \mu \mathrm{g})$, erythromycin $(100 \mu \mathrm{g})$, neomycin $(120 \mu \mathrm{g})$, norfloxacin $(10 \mu \mathrm{g})$, imipenem $(10 \mu \mathrm{g})$ and tetracycline $(10 \mu \mathrm{g})$. The zone diameters for individual antimicrobial agents were then translated into susceptible, intermediate or resistant categories according to the interpretation table supplied by the manufacturer (Oxoid limited, England).

\section{RESULTS}

Isolation of Vibrio cholerae. Typical colonies appeared small (2-3 $\mathrm{mm})$, circular, and yellow on TCBS and small (1-2 mm), circular, and black centered colonies on TTGA media were presumptively selected as $V$. cholerae. Detailed biochemical study revealed that all the strains had the biochemical characteristics typical to that of $V$. cholerae (Table 1).

Enumeration of $V$. cholerae from different excreta samples. Different excreta and biocompost samples were examined for the presence of $V$. cholerae. Human excreta samples exhibited higher count than the other samples ranging from $1.2 \times 10^{6}$ to $2.2 \times 10^{8} \mathrm{cfu} / \mathrm{g}$ (Table $2)$. The load of $V$. cholerae from poultry excreta samples ranged from 0 to $5.9 \times 10^{7} \mathrm{cfu} / \mathrm{g}$ whereas the load for cow dung samples were ranging from $4.8 \times 10^{5}$ to $1.1 \times 10^{7} \mathrm{cfu} / \mathrm{g}$. Compost samples had the lower $V$. cholerae load ranging from nil to $2.2 \times 10^{3} \mathrm{cfu} / \mathrm{g}$ (table
TABLE 2. Total count of $V$. cholerae (cfu/g) from poultry excreta, human excreta and cow-dung samples.

\begin{tabular}{|c|c|c|}
\hline Sample no. & $\begin{array}{c}\text { Total viable bacteria } \\
\text { (cfu/g) }\end{array}$ & $\begin{array}{c}\text { Load of } V . \text { cholerae } \\
(\mathrm{cfu} / \mathrm{g})\end{array}$ \\
\hline 1 & $4.6 \times 10^{9}$ & $2.2 \times 10^{8}$ \\
\hline 2 & $3.8 \times 10^{8}$ & $6.9 \times 10^{7}$ \\
\hline 3 & $5.3 \times 10^{9}$ & $1.2 \times 10^{7}$ \\
\hline 4 & $1.1 \times 10^{9}$ & $2.5 \times 10^{7}$ \\
\hline 5 & $2.4 \times 10^{9}$ & $1.4 \times 10^{8}$ \\
\hline 6 & $5.8 \times 10^{8}$ & $2.2 \times 10^{7}$ \\
\hline 7 & $1.2 \times 10^{9}$ & $1.1 \times 10^{7}$ \\
\hline 8 & $5.4 \times 10^{8}$ & $6.1 \times 10^{6}$ \\
\hline 9 & $1.9 \times 10^{9}$ & $1.1 \times 10^{7}$ \\
\hline 10 & $1.5 \times 10^{8}$ & $1.2 \times 10^{6}$ \\
\hline 11 & $1.2 \times 10^{9}$ & $1.8 \times 10^{7}$ \\
\hline 12 & $8.4 \times 10^{9}$ & $1.4 \times 10^{8}$ \\
\hline 13 & $3.8 \times 10^{8}$ & $1.1 \times 10^{7}$ \\
\hline 14 & $2.2 \times 10^{8}$ & $3.6 \times 10^{6}$ \\
\hline 15 & $7.3 \times 10^{6}$ & $5.8 \times 10^{5}$ \\
\hline 16 & $1.4 \times 10^{7}$ & $4.8 \times 10^{5}$ \\
\hline 17 & $3.7 \times 10^{8}$ & $4.5 \times 10^{6}$ \\
\hline 18 & $1.1 \times 10^{8}$ & $3.4 \times 10^{6}$ \\
\hline 19 & $1.5 \times 10^{8}$ & $1.1 \times 10^{6}$ \\
\hline 20 & $2.6 \times 10^{7}$ & $5.3 \times 10^{5}$ \\
\hline 21 & $8.8 \times 10^{7}$ & $1.0 \times 10^{7}$ \\
\hline 22 & $6.1 \times 10^{8}$ & $4.1 \times 10^{6}$ \\
\hline 23 & $5.7 \times 10^{7}$ & $3.6 \times 10^{6}$ \\
\hline 24 & $3.2 \times 10^{8}$ & $5.2 \times 10^{6}$ \\
\hline 25 & $1.2 \times 10^{7}$ & $5.7 \times 10^{6}$ \\
\hline 26 & $3.6 \times 10^{8}$ & $5.6 \times 10^{7}$ \\
\hline 27 & $1.1 \times 10^{9}$ & $4.9 \times 10^{7}$ \\
\hline 28 & $1.3 \times 10^{6}$ & 0 \\
\hline 29 & $7.4 \times 10^{7}$ & $4.9 \times 10^{6}$ \\
\hline 30 & $3.9 \times 10^{7}$ & $3.2 \times 10^{6}$ \\
\hline 31 & $1.4 \times 10^{4}$ & 0 \\
\hline 32 & $3.4 \times 10^{5}$ & 0 \\
\hline 33 & $4.1 \times 10^{8}$ & $5.5 \times 10^{7}$ \\
\hline 34 & $2.2 \times 10^{8}$ & $5.6 \times 10^{6}$ \\
\hline 35 & $3.7 \times 10^{9}$ & $5.9 \times 10^{7}$ \\
\hline 36 & $4.8 \times 10^{8}$ & $3.9 \times 10^{7}$ \\
\hline
\end{tabular}

Samples 1-12 = Human feces; Samples 13-24 = Cow dung; Samples 25-36 $=$ Poultry excreta

$3)$. However, huge array of viable bacteria was present in all the tested excreta samples (Table 2) and interestingly the load was found to be significantly reduced in the compost samples (Table 3). Such a reduction revealed the eliminatory impact of composting on microbial growth.

Antibiotic susceptibility pattern of $V$. cholerae isolates. As the resistance of $V$. cholerae against commonly used antibiotics is increasing especially in the farm animals and public health sectors, the isolates were tested to determine the pattern of their resistance against 10 commonly prescribed antibiotics belonging to different groups in the present study. All the isolates showed resistance against

TABLE 1. Biochemical characteristics of the presumptive V. cholerae isolates

\begin{tabular}{|c|c|c|c|c|c|c|c|c|c|c|c|}
\hline \multirow[t]{2}{*}{$\begin{array}{c}\text { Suspected } \\
\text { organism }\end{array}$} & \multicolumn{4}{|c|}{ TSI } & \multirow[t]{2}{*}{$\begin{array}{c}\text { Gelatinase } \\
\text { test }\end{array}$} & \multirow[t]{2}{*}{$\begin{array}{c}\text { Oxidase } \\
\text { test }\end{array}$} & \multirow[t]{2}{*}{$\begin{array}{l}\text { VP } \\
\text { Test }\end{array}$} & \multirow[t]{2}{*}{ Motility } & \multicolumn{3}{|c|}{ Salt tolerance test } \\
\hline & $\begin{array}{c}\text { Butt } \\
\text { reaction }\end{array}$ & $\begin{array}{c}\text { Slant } \\
\text { reaction }\end{array}$ & $\begin{array}{c}\mathrm{H}_{2} \mathrm{~S} \\
\text { production }\end{array}$ & $\begin{array}{c}\text { Gas } \\
\text { production }\end{array}$ & & & & & $0 \%$ & $6.5 \%$ & $8 \%$ \\
\hline V. cholerae & Y/A & Y/A & - & - & + & + & - & + & + & + & - \\
\hline
\end{tabular}


TABLE 3. Total count of $V$. cholerae (cfu/g) from compost samples.

\begin{tabular}{ccc}
\hline Sample no & $\begin{array}{c}\text { Total viable bacteria } \\
\text { (cfu/g) }\end{array}$ & $\begin{array}{c}\text { Load of } V . \text { cholerae } \\
\text { (cfu/g) }\end{array}$ \\
\hline 1 & $4.8 \times 10^{5}$ & $1.4 \times 10^{3}$ \\
2 & $2.7 \times 10^{2}$ & 0 \\
3 & $1.6 \times 10^{3}$ & 0 \\
4 & $1.5 \times 10^{4}$ & $3.2 \times 10^{2}$ \\
5 & $2.1 \times 10^{5}$ & $4.5 \times 10^{2}$ \\
6 & $5.4 \times 10^{4}$ & 0 \\
7 & $3.7 \times 10^{2}$ & 0 \\
8 & $2.2 \times 10^{2}$ & 0 \\
9 & $1.8 \times 10^{3}$ & 0 \\
10 & $3.8 \times 10^{5}$ & $2.2 \times 10^{3}$ \\
11 & $2.8 \times 10^{3}$ & 0 \\
12 & $3.3 \times 10^{4}$ & $7.6 \times 10^{2}$ \\
13 & 0 & 0 \\
14 & $2.3 \times 10^{4}$ & $2.3 \times 10^{2}$ \\
15 & $1.1 \times 10^{5}$ & $1.1 \times 10^{3}$ \\
16 & $1.7 \times 10^{4}$ & 0 \\
17 & $5.7 \times 10^{3}$ & 0 \\
18 & $4.2 \times 10^{2}$ & 0 \\
19 & 0 & 0 \\
20 & $1.2 \times 10^{5}$ & $4.1 \times 10^{2}$ \\
21 & $1.4 \times 10^{2}$ & 0 \\
22 & $4.1 \times 10^{3}$ & 0 \\
23 & $1.2 \times 10^{4}$ & $3.6 \times 10^{2}$ \\
24 & $2.3 \times 10^{2}$ & 0 \\
\hline
\end{tabular}

ampicillin, erythromycin, tetracycline, chloramphenicol, nalidixic acid and meropenem, while $90 \%$ isolates found to be resistant against cefotaxime (Figure 1). On the other hand, $100 \%$ isolates were susceptible against imipenem, neomycin and norfloxacin.

\section{DISCUSSION}

Cholera is typically transmitted by either contaminated food or water (20). People infected with cholera often have diarrhea and they further transmit infection through liquid stool contaminates water and cholera is rarely spread directly from person to person (21). Thus, to interrupt the transmission cycle, effective measures should be taken for safe supply of drinking water and food. Based on this, present study was designed to determine the load of $V$. cholerae in human excreta, poultry excreta, cowd ung and compost samples.

In this study, the prevalence of $V$. cholerae was found higher in human feces, cow dung and excreta of poultry samples. On the other hand, the load of $V$. cholerae was lower in compost samples. As most of the contaminating micro-organisms are heat-sensitive, they disappear during composting, leading to a fecal pathogen-free end product. This disappearance is defined as disinfection or sanitization (13). Therefore, compost can be a better replacement as they lower the risk of spreading of possible pathogens and reduce pollutions through waste management such as odors, ground water pollution and utilization costs $(22,23)$.

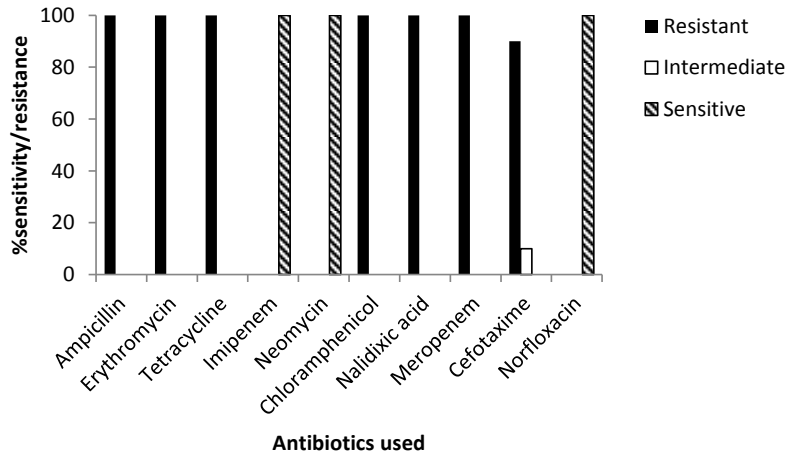

FIG. 1. Frequency of antibiotic resistance/sensitivity of $V$. cholerae isolates. The isolates were tested against ampicillin $(10 \mu \mathrm{g})$, erythromycin $(30 \mu \mathrm{g})$, tetracycline $(10 \mu \mathrm{g})$, imipenem $(10 \mu \mathrm{g})$, neomycin $(120 \mu \mathrm{g})$, chloramphenicol $(30 \mu \mathrm{g})$, nalidixic acid $(30 \mu \mathrm{g})$, meropenem $(30 \mu \mathrm{g})$, cefotaxime $(30 \mu \mathrm{g})$ and norfloxacin $(10 \mu \mathrm{g})$ by disc diffusion assay.

Furthermore, food and water contamination with antibiotic-resistant bacteria is a major threat to public health and therefore, the public health concern is increased over a concept that antibiotics fed to food producing animals may contribute to the resistance of human pathogens (24-26). V. cholerae isolates were found to be resistant against most of the commonly used antibiotics in this study which may ensure the fact that antimicrobial resistance is increasing both in the farm animal and public health sectors and emerged as a global problem in recent decades due to improper selection, indiscriminate use and misuse of antimicrobials in food producing animal farms (27-31).

In fine, our study envisaged on the urge of composting human-, animal- and poultry excreta which may further ensure a hygienic waste disposal system also being of agro-economic importance. The elimination of $V$. cholerae in the compost samples compared to the excreta samples refer to a safe and natural destruction of microorganisms in the environment, thus reducing the possibility of transmission of $V$. cholerae.

\section{REFERENCES}

1. Albert, M. J., et al. 1993. Large epidemic of cholera like disease in Bangladesh caused by Vibrio cholerae O139 synonym Bengal. Lancet 342: 387-390.

2. Janda, J. M., C. Powers, R. B. Bryant, and S.L. Abbott. 1988. Current perspective on the epidemiology and pathogenesis of clinically significant Vibrio spp. Clin. Microbiol. Rev. 1: 245-267.

3. Akond, M. A., et al. 2008. Antibiotic resistance of Vibrio cholerae from poultry sources of Dhaka, Bangladesh. Advances in Biological Research 2 (34): $60-67$.

4. Ramamurthy, T., et al. 1993. Emergence of a novel strain of Vibrio cholera with epidemic potential in Southern and Eastern India. Lancet 341: 703-704.

5. Rivas, M., et al. 1993. Cholera isolates in relation to the 'eighth Pandemic'. Lancet 342: 926-927.

6. Siddique, A. K., et al. 1996. Vibrio cholerae O139: how great is the threat of a pandemic? Trop. Med. Int. Health. 1: 393-398.

7. Faruque, S. M. and G. B. Nair. 2008. Vibrio cholerae: genomics and molecular biology. Caister Academic Press.

8. World Health Organization (WHO). 2000. Overcoming antimicrobial 
resistance: world health report on infectious diseases. World Health Organization, Geneva.

9. World Health Organization (WHO). 1999. The world drug situation WHO report. World Health Organization, Geneva.

10. Hargitai, L. 1993. The soil of organic matter content and humus quality in the maintenance of soil fertility and in environmental protection. Landscape and Urban Planning 27: 161-167.

11. Vanlauwe, B., J. Wendt, and J. Diels. 2001. Combined application of organic matter and fertilizer, p. 247-279. In Tian, G., F. Ishida, and J. D. H. Keatinge (Eds.), Sustaining soil fertility in west Africa. Soil Sci. Society of Am., Madison, Wisconsin, U. S. A.

12. Hassen, A., et al. 2001. Microbial characterization during composting of municipal solid waste. Bioresour Technol. 80 (3): 217-25.

13. De'portes, I., J. L. Benoit-Guyod, D. Zmirou, and M. C. Bouvier. 1998. Microbial disinfection capacity of municipal solid waste (MSW) composting. Journal of Applied Microbiology 85: 238-246.

14. Simmons, N.A. and F. J. Gibbs. 1979. Campylobacter spp in oven ready poultry. J. Infect. 1: 159-162.

15. Bryan, F. L. 1981. Current trends in foodborne salmonellosis in the United States and Canada. J. Food Protect. 44: 394-401.

16. Grant, I. H., N. J. Richardson, and V. D. Bokkenheuser. 1980. Broiler chickens as potential source of Campylobacter infections in humans. J. Clin. Microbiol. 11: 508-510.

17. Shanker, S., J. A. Rosenfield, G. R. Davey, and T. C. Sorrell. 1982 Campylobacter jejuni: incidence in processed broilers and biotype distribution in human and broiler isolates. Appl. Environ. Microbiol. 43: 1219-1220.

18. Cappuccino, J. G. and N. Sherman. 1996. Microbiology- A Laboratory Manual, 4th ed. The Benjamin/Cummings Publishing Co., Inc., Menlo Park, California.

19. Bauer, A. W., W. M. M. Kirby, J. C. Sheriss and M. Turck. 1966. Antibiotic susceptibility testing by standardized single disc method. Am J Clinical pathol 45: 493-496.

20. Sack, D. A., R. B. Sack, G. B. Nair, and A. K. Siddique. 2004. Cholera. Lancet 363 (9404): 223-233
21. Archivist. 1997. Cholera phage discovery. Arch Dis Child 76 (3): 274.

22. Grewal, S. K., S. Rajeev, S. Sreevatsan, and F. C. Michel. 2006. Persistence of Mycobacterium avium subsp. paratuberculosis and other zoonotic pathogens during simulated composting, manure packing, and liquid storage of dairy manure. Appl. Environ. Microbiol. 72 (1): 564-572.

23. Keener, H. M., W. A. Dick, and H. A. J. Hoitink. 2000. Composting an beneficial utilization of composted by-product materials, p. 316-341. In Power, J. F. and W. A. Dick (Eds.), Land application of agricultural, industrial, and municipal by-products. Soil Science Society of America, Madison, Wisconsin.

24 Smith, K. E., et al. 1999. Quinolone-resistant Campylobacter jejuni infections in Minnesota. N. Engl. J. Med. 340: 1525-1532.

25 Molback, K., et al. 1999. An outbreak of multidrug resistant, quinolone resistant Salmonella enteritica serotype typhimurium DT104. N. Engl. J. Med. 341: $1420-1425$.

26. Joint Expert Technical Advisory Committee on Antibiotic Resistance (JETACAR). 1999. The use of antibiotics in food producing animals: antibiotic resistant bacteria in animals and humans. Biotex, Canbbera.

27. Teuber, M. 2001. Veterinary use and antibiotic resistance. Curr. Opin Microbiol. 4: 493-499.

28. Van den Bogaard, A. E. and E. E. Stobberingh. 2000. Epidemiology of resistance to antibiotics: Links between animals and humans. Int. J. Antimicrob. Agents. 14: 327-335.

29. Aarestrup, F. M. 1999. Association between the consumption of antimicrobial agents in animal husbandry and the occurrence of resistant bacteria among food animals. Int. J. Antimicrob. Agents. 12: 279-285.

30. Angulo, F. J., K. R. Johnson, R. V. Tauxe, and M. L. Cohen. 2000. Origins and consequences of antimicrobial-resistant nontyphoidal Salmonella: implications for the use of fluoroquinolones in food animals. Microb. Drug Resist. 6: 77-83.

31. Bywater, R. J. 2004. Veterinary use of antimicrobials and emergence of resistance in zoonotic and sentinel bacteria in the EU. J. Vet. Med. B. 51: 361 363 